\title{
Impact of Shipping Knowledge and Absorptive Capacity on Logistical Value of 3PL Firms in Pakistan
}

\author{
Hira Sultan ${ }^{1 *}$, Danish Ahmed Siddiqui ${ }^{2}$ \\ ${ }^{1}$ Research Scholar, Karachi University Business School, University of Karachi, Karachi, PAKISTAN \\ ${ }^{2}$ Associate Professor, Karachi University Business School, University of Karachi, Karachi, PAKISTAN \\ *E-mail for correspondence: hira.sultan@live.com
}

https://doi.org/10.18034/abr.v7i3.15

\begin{abstract}
The purpose of this paper is to identify \& examine what types of shipping knowledge are critical to surviving in the dynamic business environment, and to investigate how the shipping knowledge affects the organizational performance. It also studies the effect of shipping knowledge and its absorptive capacity on the logistical value creation for customer satisfaction. An online survey was conducted to acquire responses from shipping companies such as freight forwarders, vessel liners, and logistic companies. Multiple regression tests were run to analyze the significance of shipping knowledge and its absorptive capacity for the creation of logistical value to provide end to end solution to the customer. The reliability test was executed, and the findings indicated that a high level of shipping knowledge has a positive impact on the logistical value of shipping companies. This study will enable 3PL firms to stay competitive in the market coping up with the rapid changes and tapping on to the untouched doors of some of the leading brands / customers in Pakistan with a variety of solutions.
\end{abstract}

Key words: Shipping Knowledge, Absorptive Capacity, Logistical Value, Competition, Shipping Industries

\section{INTRODUCTION}

Due to increased globalization these days, there has been intense competition in all industries, especially in the shipping industry. According to the shipping industrial management, the business practices that strategize towards lower price and short term based financial profits, cannot remain competitive in market in the long run and hence will need to set and achieve more strategic tasks in order to meet the business requirements and retrieve their competitiveness in market. For example, exploiting logistics value by reducing the cost of business, and enhancing the service flexibility, receptiveness and dependability would be one of the most significant demands on today's shipping companies (Lee and Song, 2010).

In addition, organizational innovation in shipping companies has also been cited as a significant strategic substitute to assist shipping companies cope with these unpredictable business environments (Chapman and Chua, 2003; Grawe, 2009; Greve, 2009). Therefore, exploiting the logistics value and comprehending an organizational innovation would be one of the main objectives that shipping companies should attain to satisfy their customers, be well integrated into the global logistics chain system, and understand long-term based strategic competitiveness.

Numerous previous studies of innovation claim that the firm's absorptive capacity has a vital impact on the capability to innovate (Cohen, et al., 1990; H.K. Knudsen and Roman, 2004). For instance, Quinn et al. (J.B. Quinn, et al, 1996) specified that the groundwork for a company's competitive advantage is to utilize its absorptive capacity to advance exceptional competitive abilities. However, they make no propositions on how to attain this. Additionally, other linked lessons present little debate on how to progress or advance absorptive capacity. In this research, we describe it as the employees' capability and inspiration to attain external knowledge and the inclination to use this knowledge in the firm's innovation capability. Absorptive capacity accentuates the capacity to acquire knowledge and the level of energy used to change it for use. Thus, a close relationship exists between knowledge and the level of absorptive capacity. In general, knowledge embraces a relationship between 
knowledge sharing, absorptive capacity, and innovation capability.

Moreover, some researchers globally have conducted studies in this context, but there has been no study on shipping knowledge, its absorptive capacity and logistical value in Pakistan. With the emerging markets and increased global competition, it is highly significant for logistics industry to keep abreast of all advancements and innovations by providing value to customers. This study aims to focus on highlighting the importance of logistical value in Pakistan.

Hence, this study will help logistics industries to understand the factors involved in impacting logistical value. In today's era, customers are very demanding, and they can simply switch to other service providers as a result of service failure. That is why it is highly imperative that third-party logistics service provider understand customer needs and provide them value along with services. This study will also assist third-party logistics provider to devise strategies and objectives benefiting them in the long run to be competitive.

\section{LITERATURE REVIEW}

\section{Theoretical Background}

Cohen \& Levinthal (1990) argues that the ability of a firm to identify and apply new external knowledge at its workplace is critical to its innovative capabilities. This capability of a firm or an individual is termed as absorptive capacity. Research indicates that firms that conduct their Research and Development are better able to utilize external information for organizational innovation. An organization's absorptive capacity does not only depend upon extracting data from external sources, but also on the transmission of knowledge within sub units. To test the forecasts for R\&D activity framework, the author has used cross-sectional survey data on technological prospect and appropriability conditions in the American manufacturing sector composed of R\&D lab managers. The results conclude that organizations are subtle to the characteristics of the learning environment in which they function. Hence absorptive capacity is one of the significant decisions of a firm towards contributing to organizational innovation activity.

Bosch et al. (1999) has researched on developing a framework in which the absorptive capacity is linked to micro and macro evolutionary effects. This paper discusses the significance of absorbing knowledge for firms that were confronted with shifting and challenging knowledge environments, and the assessment of both organizational determinants concerning their outcome and influence on a firm's absorptive capacity. However, a framework was developed to identify multiple ways in which firms can change their form as well their combinative capabilities to surge their absorptive capacity. This framework would help 3PL firms to increase their absorptive capacity by using the organizational system capabilities in a turbulent knowledge environment to acquire the required acquisition, integration and utilization of product and market knowledge process.

Fabrizio (2009) studies the relationship between a firm's knowledge absorbing capacity building activities and the hunt for innovation. It also examines the role of firm's research activities to identify external knowledge and how it can be utilized for new inventions and innovations. It indicated that the inventions \& innovations in the biotechnology and pharmaceutical sectors are linked to the research activities conducted in the biology \& chemistry departments of universities. The findings predict that internal research and collaboration with university scientist is in fact very beneficial in pacing up the innovation process.

Flint, et al, (2005) also identified that innovation in business, especially one that emphasizes on customer orientation, is highly effective to a firm's performance and its competitiveness in the market. The findings included identifying that logistical firms focused more on creating \& modifying the environment and training people to bring innovation. The author also implicated that innovation can be brought by a developing new software, designing new customer package, creating new delivery process, building new and innovative facilities, and developing new services.

\section{Empirical Studies}

Liao, et al, (2007) this research paper observes the relationship between three variables; knowledge sharing, absorptive capacity and innovation capabilities in Taiwan's knowledge-intensive industries. A model was developed for this study by data sampled from 170 Taiwanese firms. The findings suggested that knowledge sharing has a positive impact on absorptive capacity and innovation. Thus, the results indicate that knowledge sharing on innovation capability is gained through absorptive capacity and this model is the best fit.

$\mathrm{H}_{1}$ : Absorptive Capacity has a significant impact on Logistical Value.

Gil Saura, et al, (2008) this research paper aims to analyze the quality, loyalty in the supply chain and customer satisfaction in the logistics services in collaboration with information and communication technologies (ICT). The survey was conducted among manufacturers, and data was collected from 194 companies via interview. The resulting state that there is a strong and useful impact of personnel, information and order quality on satisfaction. Similarly, regarding satisfaction-loyalty relationship, it shows that satisfaction has a directly positive impact on loyalty.

$\mathrm{H}_{2}$ : Shipping Knowledge has a significant impact on Logistical Value. 


\section{Research Framework}

Hi

Absurptive Capacily

II.

Shipping

Knowledge

\section{Research Methodology}

\section{Data Collection Method}

The data related to shipping knowledge, absorptive capacity and logistical value is collected and analyzed from logistics industry employees in Karachi.

The data collection was performed through questionnaires. In this study, the 5-point Likert scale was used to indicate the level of responses to all items ( $1=$ strongly disagree to 5 strongly agree) Likert, R. (1932). The measurement scales were tested separately for their reliability and validity. The model was tested for individual hypothesis and structural fit through structural equation modeling methodology. The answers from the respondents were after collection, processed into SPSS and different analysis and tests were performed such as reliability test, factor analysis, and regression analysis to find out the reliability of the data, the relationship between the variables and the authenticity of the items of each variable.

To further explore the construct of this study, the finalized copy of the questionnaire was sent through email to the 350 employees of different companies who belonged to the logistics industry in Karachi, and 120 responded back having a response rate of $34 \%$ only.

\section{Regression Equation}

The Population Regression Equation for this model is as below;

$\mathrm{LV}=\alpha_{0}+\beta_{1} S K+\beta_{3} A C+e$

Where;

$\mathrm{LV}$, which in this model is logistical value. This variable is defined as a value to the organization where a company provides speed to services, provides services on time, and provides customized services to the customer.

SK, which in this model is "Shipping Knowledge." This variable in the study is defined as General information or know-how about the shipping industry, e.g., new trends, business culture or practice of the market, and governmental regulations of the industry. This model also includes information or know-how about customer demands on shipping services, information or know-how about strategy and behavior of competitors and information or know-how about operational skills, planning and information technology in shipping operations.
$\mathrm{AC}$, which in this model is "Absorptive Capacity" is related to the ability of a firm to absorb knowledge, where people apply knowledge to the work on daily basis. It also includes training of employees so that they are fully equipped to perform specific tasks.

\section{Data AnAlysis}

In this section, we analyzed factors that impact logistical value in 3PL firms of Pakistan logistics industries in the context of Karachi.

Table 1: Distributions of Questionnaires

\begin{tabular}{|l|c|}
\hline & Number \\
\hline Questionnaires distributed & 350 \\
\hline Total response & 120 \\
\hline Total response rate & $35 \%$ \\
\hline
\end{tabular}

Table 2: Profile of the respondents

\begin{tabular}{|l|c|c|c|}
\hline $\begin{array}{l}\text { Respondent's } \\
\text { profile }\end{array}$ & Categories & Frequency & Percent \% \\
\hline \multirow{4}{*}{ Age } & 20-30 years & 70 & 58.3 \\
\cline { 2 - 4 } & 31-40 years & 30 & 25 \\
\cline { 2 - 4 } & $41-50$ years & 20 & 16.7 \\
\cline { 2 - 4 } & 51 and above & 0 & 0 \\
\hline \multirow{4}{*}{ Designation } & Executive & 84 & 70.8 \\
\cline { 2 - 4 } & Assistant Manager & 30 & 25 \\
\cline { 2 - 4 } & Manager & 5 & 4.2 \\
\cline { 2 - 4 } Organizational & Head of department & 0 & 0 \\
\cline { 2 - 4 } & Less than 2 years & 15 & 12.5 \\
\cline { 2 - 4 } & 2-5 Years & 45 & 37.5 \\
\cline { 2 - 4 } & 6-12 Years & 35 & 29.2 \\
\cline { 2 - 4 } & 13-19 Years & 20 & 16.7 \\
\cline { 2 - 4 } & 20 years or more & 5 & 4.1 \\
\hline
\end{tabular}

Table 3: Profile of the respondents (Reliability Statistics)

\begin{tabular}{|l|c|c|}
\hline Variables & Cronbach's alpha & N of items \\
\hline SK & 0.669 & 4 \\
\hline AC & 0.606 & 3 \\
\hline LV & 0.863 & 5 \\
\hline Overall Reliability & 0.768 & 12 \\
\hline
\end{tabular}

The industry-wide survey was completed by 120 employees from various logistical organizations in Karachi. $58.3 \%$ of the respondents who filled the survey were in the age bracket of 20-30 years, 25\% in the age bracket of $31-40$ years while only $16.7 \%$ of the respondents were in the age bracket of 41-50 years.

The survey also indicated that $70.8 \%$ of the respondents were at the designation of an Executive, 25\% respondents were Assistant Managers while only 4.2\% were Managers.

Respondents indicated that their industry experience ranged from Zero to 20 years. $12.5 \%$ of the respondents had a working experience of fewer than 2 years, $37.5 \%$ respondents had a working experience of 2 years to 5 years, $29.2 \%$ of the respondents had working experience of 6 years to 12 years, $16.7 \%$ of the respondents had a working experience of 13 
years to19 years, while only $4.1 \%$ of the respondents had $20+$ years working experience.

Table 3 provides the value of Cronbach's alpha for all the variable which is 0.768 . It appears from the table that the values of Cronbach's alpha of SK, AC, and LV range from 0.669 to 0.863 (Nunnally and Bernstein, 1978). Thus it can be concluded that the measures have an acceptable level of reliability.

We have performed factor analysis which assists in reducing a large set of data into a smaller number of components that involves some associated variables (Pallant, 2005).

Table 4: KMO and Bartlett's Test

$+$\begin{tabular}{|l|c|}
\hline Kaiser-Meyer-Olkin Measure of & 0.692 \\
\hline Sampling Adequacy & \\
\hline Bartlett's Test of Sphericity & 830.897 \\
Approx. Chi-Square & 66 \\
Degree of freedom & .000 \\
\hline Sig. value & \\
\hline
\end{tabular}

Table 4 shows the Kaiser-Meyer-Olkin Measure of Sampling Adequacy (KMO) for this study was high as 0.692 whereas Bartlett's Test of Sphericity was significant.

Table 5: Factor Analysis of Correlation Matrix

\begin{tabular}{|l|c|c|c|}
\hline Factor Analysis & \multicolumn{2}{|c|}{ Component } \\
\cline { 2 - 4 } & 1 & 2 & 3 \\
\hline $\begin{array}{l}\text { General information or know-how } \\
\text { about the shipping industry, e.g., } \\
\text { new trends, business culture or } \\
\text { practice of the market, and } \\
\text { governmental regulations of the } \\
\text { industry. }\end{array}$ & & & \\
\hline $\begin{array}{l}\text { Useful information or know-how } \\
\text { about customer demands on } \\
\text { shipping services. }\end{array}$ & & .726 & \\
\hline $\begin{array}{l}\text { Useful information or know-how } \\
\text { about strategy and behavior of } \\
\text { competitors. }\end{array}$ & & .778 & \\
\hline $\begin{array}{l}\text { Useful information or know-how } \\
\text { about operational skills, planning } \\
\text { and information technology in } \\
\text { shipping operations. }\end{array}$ & & .681 & \\
\hline $\begin{array}{l}\text { Our company proactively applies } \\
\text { new knowledge to our work. }\end{array}$ & & .434 & .712 \\
\hline $\begin{array}{l}\text { Our company trains employees well } \\
\text { when applying new knowledge. }\end{array}$ & & & .837 \\
\hline $\begin{array}{l}\text { Our company invests a lot of money } \\
\text { to R\&D expenditure. }\end{array}$ & & & .645 \\
\hline $\begin{array}{l}\text { Our company provides our service } \\
\text { on time. }\end{array}$ & .812 & & \\
\hline $\begin{array}{l}\text { Our company provides customized } \\
\text { services responding to various } \\
\text { customer demands. }\end{array}$ & .816 & & \\
\hline
\end{tabular}

\begin{tabular}{|l|l|l|l|l|}
\hline $\begin{array}{l}\text { Our company flexibly respond to } \\
\text { unexpected circumstances or }\end{array}$ & .729 & & \\
volatile customer needs. & & & \\
\hline $\begin{array}{l}\text { Our company provides accurate } \\
\text { and reliable information to our } \\
\text { customers. }\end{array}$ & .771 & & \\
\hline $\begin{array}{l}\text { Our company provides speedy } \\
\text { services. }\end{array}$ & .831 & & \\
\hline
\end{tabular}

Table 5 Factor loadings for logistical value in the logistics industry in the context of Karachi. Notes: Extraction Method: Principle axis factoring, Rotation method, Varimax with Kaiser-Meyer-Olkin Measure of Sampling Adequacy (KMO) and Bartlett's Test of Sphericity.

Table V illustrates all variables that are Shipping Knowledge, Absorptive Capacity and Logistical Value of 3pl Firm. To obtain a perfect result, a factor analysis was conducted and we rotated the factors by using the varimax method to simplify our results interpretation and all items were scrutinized for patterns through factor analysis.

Table V illustrates rotated component matrix. When loading less than 0.40 were excluded, analysis resulted in a three-factor solution with a simple structure (factor loadings $>0.40$ ).

Five items loaded onto Factor 1 which is related to Shipping Knowledge, three items loaded onto Factor 2 representing Absorptive Capacity of Employees, whereas five items loaded onto factor 3 representing Logistical Value.

Table 6: Regression Analysis

\begin{tabular}{|c|c|c|c|c|}
\hline Variables & Coefficient & T. Stats & Prob. Value & VIF \\
\hline Constant & 1.905 & 3.923 & 0.000 & - \\
\hline SK & 0.350 & 3.129 & 0.002 & 1.020 \\
\hline AC & 0.205 & 3.926 & 0.000 & 1.020 \\
\hline R Square & \multicolumn{5}{|c|}{0.447} \\
\hline F-Statistics & \multicolumn{5}{|c|}{14.598} \\
\hline $\begin{array}{c}\text { Probability } \\
\text { (F-Stat) }\end{array}$ & $000^{\mathrm{b}}$ \\
\hline
\end{tabular}

Variance Inflation Factor (VIF) in our study for all independent variables is as low as 1.02 which leads to the result that multicollinearity does not exist. $R$ square in this study is 0.447 since cross-sectional data always have less R square (Reisinger and Turner, 1997).

A multiple linear regression tests was performed to study the relationship between shipping knowledge and absorptive capacity with Logistical Value.

Value of coefficient or slope represents the relationship between the variables. With the demographic variables included, Table VI illustrates the results of regression analysis which depicts that coefficients of Shipping Knowledge $(\beta=.350)$ and Absorptive Capacity $(\beta=.205)$ are positive hence, there is a positive relationship between dependent variable (Logistical Value) and Independent variables (Shipping Knowledge and Absorptive 
Capacity). As we already know that in multiple linear regressions, the sign of coefficient whether it is negative or positive give us the direction of the effect. The results depicted that shipping companies who have good shipping knowledge have a very positive impact on creating logistical value.

We can clearly observe that Significance F value is less than 0.1 which states that combined effect of all independent variable is significant. According to the results obtained, regression equation is as follows;

$\mathrm{IP}=1.905+(0.350) S K+(0.205) A C+e$

To better understand this study, Table VI results exhibited that Shipping Knowledge has a positive and significant $(\beta$ $=0.350, p<0.1$ ) impact on Logistical Value of $3 p l$ firms thus supporting the hypothesis H1. This model indicates that logistics companies who have more shipping knowledge such as general information about the shipping industry like the new market trend, business culture or market practice, competitors, etc. are more likely to create value for their customers. Absorptive Capacity also has a positive and significant $(\beta=0.205, p<0.1)$ impact on the Logistical Value of $3 \mathrm{pl}$ firms thus supporting the hypothesis H2. This model indicates that the more a logistical company invests on their employees, by training and guiding them on the processes so that they apply that knowledge on their work place, the more the company is likely to progress towards providing value to their customers.

\section{Conclusion}

We conducted this study to identify the relationship between shipping knowledge and absorptive capacity of employees to logistical value of $3 \mathrm{pl}$ firm in Pakistan. It is proved from the analysis that shipping knowledge and absorptive capacity have a positive and significant impact on the logistical value of the $3 \mathrm{pl}$ firms of Pakistan.

There are many challenges faced by logistics industry. The organization always want to gain a competitive advantage over others and create logistical value to satisfy their customers. For this purpose, shipping industry knowledge such as the updated market trends, the competition and business culture, the end to end solution to the customers and how to retain them, is most essential towards gaining value and providing satisfaction to customers. Moreover, logistical industries of Pakistan should invest more on training their employees into skillful and knowledgeable personnel so that their learning can be applied over workplace, they can create value for their customers and provide them complete solution in order to satisfy the customers and retain them.

While we assume that the entire purpose of the study has been achieved and completed successfully, there are certain limitations that our study encountered. The data in this study is obtained from convenience sample which reduces the ability of the result to be generalized. However, the data should rather be obtained from random sampling so the results could be generalized. There is more to be considered, all the measures in the study are respondent's perception based and are thus it contains chances of biases. In Pakistan, logistics industry is still evolving, and there are very few companies in Karachi who are engaged in logistical activities. Thus, we were not able to reach all the logistical companies in Pakistan.

\section{Recommendations and Policy Making}

This study has concluded that logistical value is always influenced by external factors; shipping knowledge and employee's absorptive capacity are the factors that directly influence the logistical value created to satisfy customers. Thus, we recommend that logistics companies in Pakistan should regularly conduct training sessions for their employees to guide and train them of the latest shipping trends and process, and also conduct mutual discussions so that all the employees can brainstorm ideas to attract and win customers providing them logistical value and retain the for future. The shipping knowledge gained by the trainings and discussions, should be applied to workplace on a daily basis to ensure that a company moves ahead of its competitors when it comes to providing value to customers.

\section{Future Research}

Finally, we recommend that our study addressed only one dimension of logistical value of $3 \mathrm{pl}$ firms in Pakistan that was conducted on the basis of convenience sampling. Thus it is recommended that future study should aim to consider random sampling from all over Pakistan so that results could be more generalized.

\section{REFERENCES}

Bosch, V. D., Volberda. F. A., \& De Boer, M. (1999). Coevolution of firm absorptive capacity and knowledge environment: Organizational forms and combinative capabilities. Organization science, 10(5), 551-568.

Chapman, C., \& Chua, W. F. (2003). Technology-Driven Integration, Automation, and Standardization of Business Processes. A. Bhimani (Ed.), Management accounting in the digital economy, 74-94.

Cohen, W. B., Spies, T. A., \& Bradshaw, G. A. (1990). Semivariograms of digital imagery for analysis of conifer canopy structure. Remote Sensing of Environment, 34(3), 167-178.

Fabrizio, K. R. (2009). Absorptive capacity and the search for innovation. Research Policy, 38(2), 255-267.

Flint, D. J., Larsson, E., Gammelgaard, B., \& Mentzer, J. T. (2005). Logistics innovation: a customer value-oriented social process. Journal of business logistics, 26(1), 113-147.

Gil Saura, I., Servera Frances, D., Berenguer Contri, G., \& Fuentes Blasco, M. (2008). Logistics service quality: a new way to loyalty. Industrial Management \& Data Systems, 108(5), 650-668.

Grawe, S.J. (2009), "Logistics innovation: a literature-based conceptual framework", The International Journal of Logistics Management, Vol. 20 No. 3, pp. 360-377.

Greve, H. R. (2009). Bigger and safer: The diffusion of competitive advantage. Strategic Management Journal, 30(1), 1-23. 
H.K. Knudsen, and P.M. Roman, Modeling the use of innovations in private treatment organizations: the role of absorptive capacity, Journal of Substance Abuse Treatment 26 (2004) 353-61.

J.B. Quinn, P. Anderson, and S. Finkelstein, Managing professional intellect: making the most of the best, Harvard Business Review 74 (1996) 71-80.

Lee, E.S., and Song, D.W. (2010), "Knowledge management for maritime logistics value: discussing conceptual issues", Maritime Policy and Management, Vol. 37 No. 6, pp. 563-583.

Liao, S. H., Fei, W. C., \& Chen, C. C. (2007). Knowledge sharing, absorptive capacity, and innovation capability: an empirical study of Taiwan's knowledge-intensive industries. Journal of information science, 33(3), 340-359.

Nunnally, J. C., \& Bernstein, I. H. (1978). Psychometric theory.

Pallant, J. (2005). SPSS survival manual: A step guide to data analysis using SPSS for Windows version 12.

Reisinger, Y., \& Turner, L. (1997). Cross-cultural differences in tourism: Indonesian tourists in Australia. Tourism Management, 18(3), 139-147.

W. Cohen and D. Levinthal, Absorptive capacity: a new perspective on learning and innovation, Administrative Science Quarterly 35 (1990) 128-52.

$--0--$

\section{APPENDIX}

\section{Questionnaire on}

"Impact of shipping knowledge and absorptive capacity on logistical value of 3pl firms in Pakistan"

\begin{tabular}{|c|c|}
\hline Age & 20-30 years / 31-40 years / 41-50 years / 51 and Above \\
\hline Designation & Executive/Assistant Manager/Manager/Head of Dept. or Top-Level Management \\
\hline Work Experience & $<2$ years/2-5 years/6-12 years/13-19 years/20 year and above \\
\hline
\end{tabular}

Please indicate the extent to which your company owns the following knowledge (from $1=$ few, to $5=$ very much).

\section{Shipping Knowledge}

\begin{tabular}{|c|c|c|c|c|c|c|}
\hline 1 & $\begin{array}{l}\text { General information or know-how about the shipping industry, e.g. new trends, } \\
\text { business culture or practice of the market, and governmental regulations of the } \\
\text { industry. }\end{array}$ & SD & D & $\mathbf{N}$ & A & SA \\
\hline 2 & Useful information or know-how about customer demands on shipping services & SD & $\mathbf{D}$ & $\mathbf{N}$ & $\mathbf{A}$ & SA \\
\hline 3 & Useful information or know-how about strategy and behavior of competitors & SD & D & $\mathbf{N}$ & A & SA \\
\hline 4 & $\begin{array}{l}\text { Useful information or know-how about operational skills, planning and } \\
\text { information technology in shipping operations }\end{array}$ & SD & D & $\mathbf{N}$ & $\mathbf{A}$ & SA \\
\hline
\end{tabular}

Absorptive Capacity

\begin{tabular}{|c|c|c|c|c|c|c|}
\hline 1 & Our company proactively applies new knowledge to our work. & SD & D & $\mathbf{N}$ & $\mathbf{A}$ & SA \\
\hline 2 & Our company trains employees well when applying new knowledge. & SD & D & $\mathbf{N}$ & $\mathbf{A}$ & SA \\
\hline 3 & Our company invests a lot of money to R\&D expenditure. & SD & D & $\mathbf{N}$ & $\mathbf{A}$ & SA \\
\hline
\end{tabular}

\section{Logistical Value}

\begin{tabular}{|c|c|c|c|c|c|c|}
\hline 1 & Our company provides our service on time. & SD & $\mathrm{D}$ & $\mathbf{N}$ & $\mathbf{A}$ & SA \\
\hline 2 & $\begin{array}{l}\text { Our company provides customized services responding to various customer } \\
\text { demands. }\end{array}$ & SD & D & $\mathbf{N}$ & $\mathbf{A}$ & SA \\
\hline 3 & $\begin{array}{l}\text { Our company flexibly respond to unexpected circumstances or volatile } \\
\text { customer needs. }\end{array}$ & SD & D & $\mathbf{N}$ & $\mathbf{A}$ & SA \\
\hline 4 & Our company provides accurate and reliable information to our customers. & SD & D & $\mathbf{N}$ & $\mathbf{A}$ & SA \\
\hline 5 & Our company provides speedy services. & SD & $\mathrm{D}$ & $\mathbf{N}$ & $\mathbf{A}$ & SA \\
\hline
\end{tabular}

Online Archive: https://abc.us.org/ojs/index.php/abr/issue/archive

\section{Sf) Worldcat Google scholar

